\title{
Factors Affecting the Utilization of Outpatient Health Services and Importance of Health Insurance
}

\author{
Farhad Lotfi, ${ }^{1}$ Soraya Nouraei Motlagh, ${ }^{2}$ Ghadir Mahdavi, ${ }^{3}$ Khosro Keshavarz, ${ }^{1}$ Mohammad Hadian, ${ }^{4}$ \\ and Hassan Abolghasem Gorji ${ }^{5,}$ \\ ${ }^{1}$ Health Human Resources Research Center, School of Management \& Information Sciences, Shiraz University of Medical Sciences, Shiraz, IR Iran \\ ${ }^{2}$ Public Health Department, School of Health and Nutrition, Social Determinants of Health Research Center, Lorestan University of Medical Sciences, Khorramabad, IR Iran \\ ${ }^{3}$ ECO College of Insurance, Allameh Tabataba'i University, Tehran, IR Iran \\ ${ }^{4}$ Department of Health Economics, School of Health Management and Information Sciences, Iran University of Medical Sciences, Tehran, IR Iran \\ ${ }^{5}$ Health Management and Economics Research Center, Iran University of Medical Sciences, Tehran, IR Iran \\ "Corresponding author: Hassan Abolghasem Gorji, Department of Health Services Management, School of Health Management and Information Sciences, Iran University of \\ Medical Sciences, No. 6, Rashid Yasemi st., Vali-e-asr Ave., Tehran, IR Iran. Tel: +98-2188794302, Fax: +98-2188883334. E-mail: gorji.h@iums.ac.ir
}

Received 2016 December 03; Revised 2017 April 09; Accepted 2017 April 29.

\begin{abstract}
Background: Research on the utilization of health services provides an opportunity to identify and determine the quantity and quality of factors, which can facilitate or debilitate access to services. Policymakers believe that factors affecting the use of health services should be quantified in order to allocate further resources to indicators, which can help reduce inequalities. This study aimed to investigate factors affecting the utilization of outpatient services and to determine the effect of health insurance on financial support for individuals.

Methods: The present study included all Iranian households, which had been recruited by the Statistical Center of Iran in 2012 2013. The data were analyzed in 2 logit models and divided into urban and rural areas.

Results: According to the results, basic and full insurance coverage was the main factor, influencing the utilization of outpatient health services. Furthermore, age composition of households affected their utilization of these services. More precisely, households with more members aged $<5$ or $>65$ years tended to use outpatient services more frequently. In addition, households with female heads and those from higher decile groups were more likely to use outpatient services. On the contrary, educational level and household size had negative effects on demand for outpatient health services.

Conclusions: Based on the results, there was a significant association between social and economic status and utilization of outpatient services. For decreasing the observed inequalities, policymakers should pay particular attention to households with low income and members aged $<5$ or $>65$ years and provide access to health services for these groups (eg, access to family physicians).
\end{abstract}

Keywords: Utilization, Health Insurance, Outpatient Health Services

\section{Background}

One of the objectives in the evaluation of people's demands and utilization of health services is to identify major factors influencing the use of these services. A better understanding of these factors helps stakeholders and policymakers have a comprehensive image of different variables influencing the utilization of health services; in addition, it can help predict the use of these services in different populations. Use the limited resources efficiently and spend public funds on the suitable and effective services, as well as. Identification of these factors is a method for accurate estimation of health resources $(1,2)$ and macroeconomic policymaking in the health sector (3). In fact, research on the utilization of health services helps identify factors, which facilitate or prevent access to these services (4).

Based on the findings of previous studies, a number of predisposing factors (eg, gender, place of residence, occupation, and educational level), empowering factors (eg, health insurance and income), and need-related factors have been identified as predictors for utilization of health services $(5,6)$. In this regard, one of the major factors affecting the utilization of health services is socioeconomic status.

Recent studies have indicated that utilization of health services is associated with people's gender, place of residence, and socioeconomic status (7). For instance, women's low social status in some regions might discourage them against the use of health services. This problem is exacerbated when other household members (especially husbands) are reluctant to accept the costs of health services and refuse to devote enough time to a long-term treatment (8).

Previous findings have also demonstrated the positive 
relationship between age and costs of health treatments (9). Moreover, previous studies have indicated that high costs of treatment are a great challenge for underprivileged families, thereby necessitating some strategies to extend the insurance coverage for these households (10). In addition, research shows that people with insurance are more inclined to utilize health services (11).

Health insurance coverage shows socioeconomic inequalities in providing health services (12). Therefore, in countries where all citizens are under health insurance coverage, there is little difference among different socioeconomic classes in terms of utilization of health services (13). Many countries have already implemented social insurance schemes to decrease financial challenges against the use of health services (14).

After the Iranian Revolution, health insurance coverage and health indicators were improved, which facilitated more access to health services for different groups of people. Nevertheless, inequality among different social classes has not been reduced, which indicates considerable differences among these groups in terms of utilization of health services (15).

Many governmental agencies and international organizations have made attempts to decrease inequality among different social classes with regard to the use of health services (16). According to the health innovation and science development plan, reducing inequality is one of the main challenges of Iran's health sector (17). As a result, policymakers believe that factors influencing the utilization of health services should be quantified in order to allocate further resources to indicators, which require additional support (7).

In developed countries, different factors, which can affect the utilization of health services in different situations, have been identified and analyzed. Nevertheless, these efforts are insignificant in developing countries (18). Therefore, studies on the utilization of health services do not have a long history in these countries (19).

Utilization of health services is a complicated subject, which is influenced by numerous factors. Therefore, every study on this subject should consider a definite number of factors, which may influence the utilization of health services (20). In the present study, we aimed to identify the main variables influencing the utilization of health services in the light of previous studies. We also reviewed the available literature, expert viewpoints, and available information on a national scale.

\section{Methods}

The primary objective of this study was to identify factors influencing the utilization of outpatient services in ur- ban and rural areas of Iran, using logit econometric model. An analytical descriptive design was adopted in this study. All Iranian households, which had been recruited by the statistical center of Iran in 2012 - 2013, were included in the study. Data related to the households over the past month were gathered by questioners. The final sample included 17,364 urban and 16,602 rural families.

The data were analyzed in 2 logit models and categorized into urban and rural classes. In this study, the dependent variable was utilization of outpatient services (lack of utilization, 0 ; utilization, 1 ). If $\mathrm{P}_{\mathrm{i}}$ is the probability of utilization of outpatient services and $1-\mathrm{P}_{\mathrm{i}}$ is the probability of not utilizing these services, the logit model can be illustrated as follows:

$$
\begin{aligned}
\frac{P_{i}}{1-P} & =\frac{1+e^{z_{i}}}{1+e^{-z_{i}}} \\
& =e^{z_{i}}
\end{aligned}
$$

If the normal logarithm of cumulative distribution function is applied, the following equation can be obtained:

$$
\begin{aligned}
L_{i} & =\ln \left(\frac{P_{i}}{1-P_{i}}\right) \\
& =z_{i} \\
& =\beta_{1}+\beta_{2} x_{i}+u_{i}
\end{aligned}
$$

The parameters of the logit model are estimated, based on the maximum likelihood method, which is the most common technique for estimating logit models. It is difficult to interpret the logit model coefficients since they are estimated based on a binary model, which cannot be interpreted as the marginal effect on the dependent variable. The following equation was used to estimate the marginal effect of the independent variable Xi on conditional probability $P_{\mathrm{i}}$ :

$\frac{\partial E\left(Y \vdots X_{i}^{\prime} \beta\right)}{\partial X_{i}}=f\left(X_{i}^{\prime} \beta\right) \beta_{i}$

where $\mathbf{f}\left(\mathrm{X}_{\mathbf{i}}^{\prime} \beta\right)$ is the density function or derivative of the logistic cumulative distribution function $(21,22)$. In this study, we first aimed to determine the probability of utilization of and demand for outpatient services. In the next stage, we determined the marginal effect of each explanatory variable. The marginal effect denotes the probability of change in utilization of outpatient services because of a 1-unit increase in the explanatory variables. Other variables are described in Table 1.

Econometric methods and EView- 6 were used to perform the calculations. In each model, Hosmer-Lemeshow and Davidson-MacKinnon tests were respectively used to assess goodness of fit and heterogeneity of variances. 
Table 1. Description and Classification of Study Variables

\begin{tabular}{|c|c|}
\hline Variables & Description \\
\hline Household head's gender & 1 , male; 2 , female \\
\hline $\begin{array}{l}\text { Household head's occupational } \\
\text { status }\end{array}$ & 1, employed; 2, unemployed \\
\hline $\begin{array}{l}\text { Number of household members }< \\
5 \text { years }\end{array}$ & Number of members $<5$ years \\
\hline $\begin{array}{l}\text { Number of household members }> \\
60 \text { years }\end{array}$ & Number of members $>60$ years \\
\hline $\begin{array}{l}\text { Household head's educational } \\
\text { level }\end{array}$ & $\begin{array}{l}\text { 0, illiterate; } 1 \text {, elementary school; } 2 \text {, } \\
\text { junior high school; } 3 \text {, high school } \\
\text { diploma; } 4 \text {, associate diploma; } 5 \text {, } \\
\text { Bachelor's degree; } 6 \text {, Master's degree; } \\
\text { 7, PhD }\end{array}$ \\
\hline Household head's age & Continuous variable \\
\hline Household size & Number of household members \\
\hline Insurance coverage & $\begin{array}{l}0, \text { no coverage; } 1 \text {, basic insurance } \\
\text { coverage; } 2 \text {, full insurance coverage }\end{array}$ \\
\hline $\begin{array}{l}\text { Income decile group (total } \\
\text { household income) }\end{array}$ & Decile groups ranging from 1 to 10 \\
\hline Utilization of outpatient services & $\begin{array}{l}0, \text { no utilization; } 1 \text {, utilization of } \\
\text { outpatient services }\end{array}$ \\
\hline
\end{tabular}

\section{Results}

\subsection{Estimation of Demand for Health Services in Urban Areas}

Demands for utilization of health services were evaluated for different age groups, as presented in Table 2.

As indicated in Table 2, in total, $61.92 \%$ of households demanded outpatient health services. The greatest demand $(28.74 \%)$ was reported in households in which the head was over 60 years. Table 3 illustrates the trend for utilization of outpatient services with respect to the educational level of household heads.

According to the results presented in Table 3, higher educational level of the household head was associated with less demand for utilization of outpatient services. There was a significant association between the household head's educational level and utilization of outpatient services. Table 4 shows the results related to households from different income decile groups.

The results indicate that households from higher income decile groups had more demands for using outpatient services. The results of logit model estimation are presented in Table 5.

In Table 5, the coefficients of demand function show a significant relationship between utilization of outpatient services and some other variables, including gender, income decile groups, number of children $<5$ years, number of household members $>65$ years, basic insurance coverage, full insurance coverage, and age of the household head. Conversely, utilization of outpatient services had an inverse relationship with household size and educational level of the household head. The most significant inverse relationship was observed between utilization of outpatient services and educational level. However, there was no significant difference in the utilization of outpatient services between households with illiterate heads and those with elementary level education.

On the other hand, number of employed members in a household did not have any significant effect on the utilization of outpatient services. Therefore, the null hypothesis (prediction errors are insignificant) and goodness of fit were confirmed $(\mathrm{P}=0.4534)$. The area under the receiver operating characteristic (ROC) curve supports this hypothesis.

Estimation of demand in rural areas

Similar to urban areas, coefficients of factors, which can influence families' demands for outpatient services, were estimated using the logit model. The following tables display the results based on age, educational level, income decile group, and model estimation. The results of the analysis of relationship between demand for outpatient services and age are presented in Table 6.

As indicated in Table 6, in total, 61.45\% of households demanded outpatient services. The greatest demand (34.66\%) was reported in households with a head aged $>60$ years. This finding is in line with the results reported in urban families. In addition, Table 7 shows the demand for utilization of outpatient services with respect to the household head's educational level.

The results demonstrated that households with less educated heads demanded outpatient services more frequently than those in which the head had a higher educational level. However, since the number of people with postgraduate degrees (Master's degree and $\mathrm{PhD}$ ) is quite limited in rural areas, comparisons cannot be made among different groups in terms of utilization of outpatient services. Table 8 illustrates the results for the utilization of outpatient services, based on the income decile groups.

According to Table 8, rural households from higher income decile groups utilized outpatient services more frequently. The results of model estimation are presented in Table 9.

Table 9 shows a significant relationship between utilization of outpatient services and some other variables, including income decile group, number of children $<5$ years in the household, number of household members $>65$ years, basic insurance coverage, full insurance coverage, and household head's age. However, utilization of outpatient services was negatively associated with household size. 
Table 2. The Demand for Outpatient Services in Different Age Groups in Urban Areas ${ }^{\mathrm{a}}$

\begin{tabular}{|c|c|c|c|c|c|c|}
\hline \multirow[t]{2}{*}{ Demand } & \multicolumn{6}{|c|}{ Age, $y$} \\
\hline & $30>$ & $30-40$ & $40-50$ & $50-60$ & $>60$ & Total \\
\hline No $(0)$ & $477(7.2)$ & $1379(20.9)$ & $1828(27.6)$ & $1481(22.4)$ & $1447(21.9)$ & $6612(100)$ \\
\hline Yes (1) & $532(4.95)$ & $1938(18.02)$ & $2647(24.62)$ & $2545(23.67)$ & $3090(28.74)$ & $10752(100)$ \\
\hline
\end{tabular}

${ }^{\mathrm{a}}$ Values are expressed as No. (\%).

Table 3. The Demand for Outpatient Services in Urban Areas with Respect to the Household Head's Educational Level ${ }^{\mathrm{a}}$

\begin{tabular}{lcccccccccc}
\hline & \multicolumn{1}{c}{ Education } \\
\cline { 2 - 8 } Demand & $\mathbf{0}$ & $\mathbf{1}$ & $\mathbf{2}$ & $\mathbf{3}$ & $\mathbf{4}$ & $\mathbf{5}$ & $\mathbf{6}$ & $\mathbf{7}$ \\
\hline No(0) & $1327(20.07)$ & $1804(27.28)$ & $1005(15.20)$ & $1452(21.96)$ & $401(6.06)$ & $576(8.71)$ & $31(0.47)$ & $16(0.24)$ & $6612(100)$ & \\
Yes $(\mathbf{1})$ & $2463(22.91)$ & $3196(29.72)$ & $1594(14.83)$ & $1992(18.53)$ & $582(5.41)$ & $874(8.13)$ & $31(0.29)$ & $20(0.19)$ & $1075(100) 2$ \\
\hline
\end{tabular}

${ }^{a}$ Values are expressed as No. (\%)

Table 4. The Demand for Outpatient Services in Urban Households from Different Income Decile Groups ${ }^{\mathrm{a}}$

\begin{tabular}{lcccccccccccc}
\hline & \multicolumn{10}{c}{ Decile } \\
\cline { 2 - 10 } Demand & $\mathbf{1}$ & $\mathbf{2}$ & $\mathbf{3}$ & $\mathbf{4}$ & $\mathbf{5}$ & $\mathbf{6}$ & $\mathbf{7}$ & $\mathbf{8}$ & $\mathbf{9}$ & $\mathbf{1 0}$ & Total \\
\hline No(0) & $830(12.55)$ & $806(12.19)$ & $751(11.36)$ & $754(11.40)$ & $670(10.13)$ & $638(9.65)$ & $613(9.27)$ & $579(8.76)$ & $517(7.82)$ & 454() & $6612(100)$ \\
Yes $(\mathbf{1})$ & $907(8.44)$ & $930(8.65)$ & $985(9.16)$ & $983(9.14)$ & $1066(9.91)$ & $1,098(10.21)$ & $1124(10.45)$ & $1157(10.76)$ & $1219(11.34)$ & $1283(11.93)$ & $10752(100)$ \\
\hline
\end{tabular}

${ }^{a}$ Values are expressed as No. (\%).

Table 5. The Demand for Outpatient Services in Urban Areas ${ }^{\mathrm{a}}$

\begin{tabular}{|c|c|c|c|c|c|c|}
\hline Variables & & Coefficients & Standard Error & z Test & PValue & Marginal Effect \\
\hline Household head's gender & & 0.1168873 & 0.055354 & 2.11 & 0.035 & 0.0263107 \\
\hline Household size & & -0.071175 & 0.01254 & -5.68 & 0.000 & -0.016021 \\
\hline Decile & & 0.1442774 & 0.006882 & 20.97 & 0.000 & 0.0324761 \\
\hline Number of household members $<5$ years & & 0.2220492 & 0.035316 & 6.29 & 0.000 & 0.0499821 \\
\hline Number of household members $>60$ years & & 0.2543677 & 0.043778 & 5.81 & 0.000 & 0.0572569 \\
\hline Household head's occupation & & -0.004258 & 0.023776 & -0.18 & 0.858 & -0.000958 \\
\hline \multirow{2}{*}{ Insurance } & 1 & 0.1815243 & 0.037406 & 4.85 & 0.000 & 0.0415474 \\
\hline & 2 & 0.4075466 & 0.069885 & 5.83 & 0.000 & 0.0908227 \\
\hline \multirow{7}{*}{ Household head's educational level } & 1 & -0.033008 & 0.050969 & -0.65 & 0.517 & -0.007063 \\
\hline & 2 & -0.140113 & 0.06269 & -2.23 & 0.025 & -0.030433 \\
\hline & 3 & -0.454492 & 0.060421 & -7.52 & 0.000 & -0.102237 \\
\hline & 4 & -0.550901 & 0.085071 & -6.48 & 0.000 & -0.124915 \\
\hline & 5 & -0.617079 & 0.078044 & -7.91 & 0.000 & -0.140578 \\
\hline & 6 & -1.203162 & 0.265966 & -4.52 & 0.000 & -0.277914 \\
\hline & 7 & -1.083152 & 0.345965 & -3.13 & 0.002 & -0.250487 \\
\hline Household head's age & & 0.0051935 & 0.001797 & 2.89 & 0.004 & 0.001169 \\
\hline Intercept & & -0.468332 & 0.136126 & -3.44 & 0.001 & . \\
\hline
\end{tabular}

${ }^{\mathrm{a}}$ No. of obs., 17,364; $\mathrm{LRChi}^{2}$ (16), 803.98; Prob. > $\mathrm{Chi}^{2}, 0.000$

With respect to the household head's educational level, the results showed a significant difference between households in which the head had a high-school diploma, associate degree, or Bachelor's degree and the ones with illiterate household heads. The latter group utilized outpa- tient services less frequently than the former groups. However, no significant difference was observed between other groups with different educational levels. In addition, the number of employed household members did not affect utilization of outpatient services in rural areas. Also, in this 
Table 6. Demand for Outpatient Services in Different Age Groups in Rural Areas ${ }^{\mathrm{a}}$

\begin{tabular}{lcccccc}
\hline & \multicolumn{5}{c}{ Age, $\mathbf{c}$} \\
\cline { 2 - 6 } e Demand & $\mathbf{3 0}>$ & $\mathbf{3 0 - 4 0}$ & $\mathbf{4 0 - 5 0}$ & $\mathbf{5 0 - 6 0}$ & \multicolumn{6}{c}{ Total } \\
\hline No(0) & $369(5.77)$ & $1482(23.16)$ & $1561(24.39)$ & $1297(20.27)$ & $1691(26.42)$ & $6400(100)$ \\
Yes $(\mathbf{1})$ & $472(4.63)$ & $1959(19.20)$ & $2231(21.87)$ & $2004(19.64)$ & $3536(34.66)$ & $10202(100)$ \\
\hline
\end{tabular}

${ }^{\mathrm{a}}$ Values are expressed as No. (\%).

Table 7. The Demand for Outpatient Services in Rural Areas with Respect to Household Heads' Educational Level ${ }^{\mathrm{a}}$

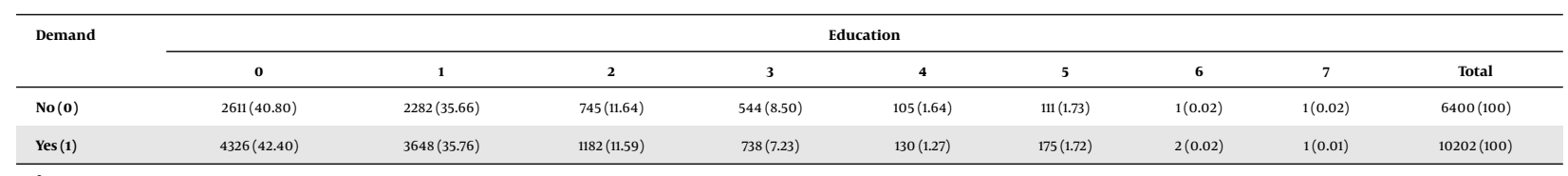

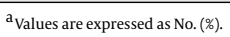

Table 8. The Demand for Outpatient Services in Rural Households from Different Income Decile Groups ${ }^{\mathrm{a}}$

\begin{tabular}{lcccccccccccc}
\hline & \multicolumn{10}{c}{ Income Decile Group } \\
\cline { 2 - 10 } Demand & $\mathbf{1}$ & $\mathbf{2}$ & $\mathbf{3}$ & $\mathbf{4}$ & $\mathbf{5}$ & $\mathbf{6}$ & $\mathbf{7}$ & $\mathbf{8}$ & $\mathbf{9}$ & $\mathbf{1 0}$ & Total \\
\hline No $(\mathbf{0})$ & $835(13.05)$ & $781(12.20)$ & $733(11.45)$ & $718(11.22)$ & $694(10.84)$ & $644(10.06)$ & $598(9.34)$ & $529(8.27)$ & $465(7.27)$ & $403(6.30)$ & $6400(100)$ \\
Yes $(\mathbf{1})$ & $826(8.10)$ & $879(8.62)$ & $927(9.09)$ & $942(9.23)$ & $966(9.47)$ & $1016(9.96)$ & $1062(10.41)$ & $1131(11.09)$ & $1195(11.71)$ & $1258(12.33)$ & $10202(100)$ \\
\hline
\end{tabular}

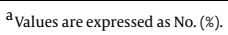

Table 9. The Results of Demand Estimation for Outpatient Services in Rural Areas ${ }^{\mathrm{a}}$

\begin{tabular}{|c|c|c|c|c|c|c|}
\hline Variables & & Marginal Effect & PValue & $\mathrm{Z}$ test & Standard Error & Coefficient \\
\hline Household head's gender & & 0.023372 & 0.056 & 1.91 & 0.054824 & 0.104772 \\
\hline Household size & & -0.02901 & 0.000 & -10.91 & 0.011916 & -0.13003 \\
\hline Number of household members $<5$ years & & 0.043585 & 0.000 & 5.79 & 0.033734 & 0.195382 \\
\hline Number of household members $>60$ years & & 0.084798 & 0.000 & 9.2 & 0.041311 & 0.380133 \\
\hline Household head's occupation & & 0.003048 & 0.486 & 0.7 & 0.019606 & 0.013663 \\
\hline \multirow{2}{*}{ Insurance } & 1 & 0.067792 & 0.000 & 5.65 & 0.052527 & 0.296969 \\
\hline & 2 & 0.102717 & 0.000 & 3.61 & 0.126498 & 0.457002 \\
\hline \multirow{6}{*}{ Household head's educational level } & 1 & 0.008146 & 0.412 & 0.82 & 0.044821 & 0.036756 \\
\hline & 2 & 0.009756 & 0.496 & 0.68 & 0.064759 & 0.044055 \\
\hline & 3 & -0.04757 & 0.004 & -2.87 & 0.07301 & -0.20983 \\
\hline & 4 & -0.12393 & 0.000 & -3.72 & 0.144508 & -0.5372 \\
\hline & 5 & -0.07598 & 0.014 & -2.46 & 0.134902 & -0.33235 \\
\hline & 7 & -0.23524 & 0.471 & -0.72 & 1.41551 & -1.02128 \\
\hline Household head's age & & 0.001332 & 0.001 & 3.27 & 0.001829 & 0.005972 \\
\hline Intercept & & . & 0.000 & -6.19 & 0.142474 & -0.88213 \\
\hline
\end{tabular}

${ }^{\mathrm{a}}$ No. of obs., $16602 ; \mathrm{LRChi}^{2}(16), 999.79 ;$ Prob. $\mathrm{Chi}^{2}, 0.000$.

model, goodness of fit was confirmed based on the area under the ROC curve and Hosmer-Lemeshow test $(\mathrm{P}=0.1778)$.

\section{Discussion and Conclusion}

Similar to all types of goods and services, providing outpatient services requires financial resources, which can be provided through governmental and organizational 
support, insurance agencies, and supportive institutions. Therefore, it is crucial to study variables, which may influence the utilization of outpatient services.

Based on the findings of the current study, basic and full insurance coverage is the main factor influencing the utilization of outpatient services. This can be explained in the light of financial support individuals receive when they enjoy basic and full coverage by insurance agencies. On the other hand, full insurance coverage causes moral concerns in the insurance system. In general, one must be cautious while interpreting the positive impact of insurance coverage. On one hand, it reduces the costs of service utilization, and consequently, contributes to more frequent use of services. On the other hand, continuous use of insurance (ie, using insurance even when not necessary) jeopardizes the financial stability of insurance organizations.

Various studies have demonstrated the positive effect of insurance coverage on utilization of health services. Saeed et al. indicated that insurance coverage increased the chance of using health services in Ghana (23). Moreover, Algazzar showed that insurance coverage was the main factor influencing the utilization of health services in Lebanon (24). Woods et al. also revealed that children with insurance coverage used outpatient services 4 times more frequently than those who did not have any insurance coverage (25).

The second most important factor influencing the utilization of health services was the age composition of families. More precisely, households with more members $<5$ or $>65$ years tended to use outpatient services more frequently. This finding indicates that these 2 groups ( $<5$ or $>65$ years) need more access to outpatient services. In addition, the household head's age was another factor influencing the utilization of outpatient services. Its effect was however less significant than the other 2 age groups (ie, $<5$ years and $>65$ years). These findings are in line with those reported by Pourreza (26), Ishida (27), and Chaze (28).

The results of data analysis showed that household income significantly affected the utilization of outpatient services. This finding is in line with studies by Hosseini Nasab and Varahrami (11), Chau (29), Blackwell et al. (30), and Singh et al. (31). However, Kavosi et al ( 2015) reported negative horizontal inequity index of outpatient utilization in Shiraz which implied no inequality (32). Moreover, the present study showed that utilization of outpatient services was more frequent among households with female heads. This shows that women are more sensitive towards the necessity of these services. Falkingham et al. also studied the relationship between household head's gender and demand for outpatient services in Kyrgyzstan and showed that women more frequently visited health cen- ters for medical advice in comparison with men (33). Another study conducted in Brazil showed that women received more outpatient services than men (34).

Households with more educated heads used outpatient services less frequently than those with lower educational levels. This might be attributed to the greater attention of educated households to health issues and more frequent use of preventive measures. Therefore, such households enjoy a better health status and do not necessarily need to utilize health services. These findings are in line with the results of a study by Hassanzadeh, whereas they are in contrast to some previous studies (15). It seems that knowledge improvement in the society can promote the health status and reduce the risk of diseases.

Additionally, the coefficient of household size showed a significant negative impact on utilization of outpatient services. This can be explained by the lower per capita household expenditures in larger families. In fact, since fewer financial resources are allocated to each member in large households, they are less likely to utilize outpatient services.

Generally, inequality in utilization of health services can be addressed from different perspectives. On one hand, governmental health policies (eg, use of family physicians) can be helpful in reducing inequalities. On the other hand, there are some factors, which cannot be controlled by the health sector. In order to take effective measures in this area, intersectoral collaborations are required. Therefore, studies, similar to the present one, can lead to reforms in the health sector. They can also help policymakers revise the system structure, redesign interventions, and show more effective management.

Furthermore, governments can support households in lower decile groups from deprived areas or households with more members $<5$ years or $>65$ years by providing subsidies. Through such strategies, these groups are provided with financial support and have more access to health services. In such systems, vulnerable households are charged less for health services (or even free of charge).

Identification of factors influencing the utilization of health services can also help health insurance organizations determine parameters, which have the greatest impact on the utilization of health services and can cause damage to these organizations. Accordingly, they can propose appropriate strategies to provide better insurance coverage in each area. Overall, evaluation of these risk factors shows that organizations should take risky conditions into account. They should also propose appropriate insurance fees to guarantee the clients' financial stability and pay for damages. All these measures should be implemented to enable patients, especially those from lowincome families, to have access to health services. In fact, 
this is the main objective of healthcare systems, which should not be neglected.

Overall, previous studies have focused on provincial or local information, whereas the present study was conducted on a national scale. The major limitation of the present study was that some variables, such as cultural and lifestyle factors, which affect the utilization of health services, could not be incorporated in the model.

\section{Acknowledgments}

The present study was conducted with the cooperation and support of the insurance research center, affiliated to the central insurance of Islamic Republic of Iran.

\section{Footnote}

\section{Conflicts of Interest: There are no conflicts of interest.}

\section{References}

1. Hosseinpoor AR, Naghavi M, Alavian SM, Speybroeck N, Jamshidi H, Vega J. Determinants of seeking needed outpatient care in Iran: results from a national health services utilization survey. Arch Iran Med. 2007;10(4):439-45. [PubMed: 17903047].

2. Ravangard R, Hatam N, Teimourizad A, Jafari A. Factors affecting the technical efficiency of health systems: A case study of Economic Cooperation Organization (ECO) countries (2004-10). International journal of health policy and management. 2014;3(2):63-69.

3. Ebadi FAF, Rezapour A, Abbasi BP, Safari H, Moeeni NM. Utilization of health care services in the state of Isfahan. Hospital J. 2011;1390(10):110

4. Shin H, Song H, Kim J, Probst JC. Insurance, acculturation, and health service utilization among Korean-Americans. J Immigr Health. 2005;7(2):65-74. doi: 10.1007/s10903-005-2638-4. [PubMed: 15789158].

5. Giannakopoulos G, Tzavara C, Dimitrakaki C, Ravens-Sieberer U, Tountas Y. Adolescent health care use: investigating related determinants in Greece. J Adolesc. 2010;33(3):477-85. doi: 10.1016/j.adolescence.2009.06.003. [PubMed: 19596423]

6. Montazeri A, Goshtasebi A, Vahdaninia M. Educational inequalities in self-reported health in a general Iranian population. BMC Res Notes. 2008;1:50. doi:10.1186/1756-0500-1-50. [PubMed: 18710503].

7. Mohammadbeigi A, Hassanzadeh J, Eshrati B, Rezaianzadeh A. Decomposition of inequity determinants of healthcare utilization, Iran. Public Health. 2013;127(7):661-7. doi: 10.1016/j.puhe.2013.01.001. [PubMed: 23608021].

8. Pourreza A. Health economics in developing countries, high institute of research and education, management and planning. ; 2004

9. Breyer F, Felder S. Life expectancy and health care expenditures: a new calculation for Germany using the costs of dying. Health Policy. 2006;75(2):178-86. doi: 10.1016/j.healthpol.2005.03.011. [PubMed: 15893848].

10. McIntyre D, Thiede M, Dahlgren G, Whitehead M. What are the economic consequences for households of illness and of paying for health care in low- and middle-income country contexts?. Soc Sci Med. 2006;62(4):858-65. doi: 10.1016/j.socscimed.2005.07.001. [PubMed: $16099574]$

11. Hosseini Nasab E, Varahrami V. Determinant factors on households health care expenditures in Yazd, Iran. J Health Administrat. 2010;13(40):73-9.
12. Lasser KE, Himmelstein DU, Woolhandler S. Access to care, health status, and health disparities in the United States and Canada: results of a cross-national population-based survey. Am J Public Health. 2006;96(7):1300-7. doi: 10.2105/AJPH.2004.059402. [PubMed: 16735628].

13. Palencia L, Espelt A, Rodriguez-Sanz M, Rocha KB, Pasarin MI, Borrell C. Trends in social class inequalities in the use of health care services within the Spanish National Health System, 1993-2006. Eur J Health Econ. 2013;14(2):211-9. doi: 10.1007/s10198-011-0362-7. [PubMed: 22072321].

14. Asuming PO. Three Essays on the Economics of Health in Developing Countries. Columbia University; 2013.

15. Hassanzadeh J, Mohammadbeigi A, Eshrati B, Rezaianzadeh A, Rajaeefard A. Determinants of inequity in health care services utilization in markazi province of iran. Iran Red Crescent Med J. 2013;15(5):363-70. doi: 10.5812/ircmj.3525. [PubMed: 24349720].

16. Houweling TA, Kunst AE, Mackenbach JP. Measuring health inequality among children in developing countries: does the choice of the indicator of economic status matter?. Int J Equity Health. 2003;2(1):8. doi: 10.1186/1475-9276-2-8. [PubMed:14609435].

17. Larijani B, Majdzadeh R, Delavari AR, Rajabi F, Khatibzadeh S, Esmailzadeh $\mathrm{H}$, et al. Iran's health innovation and science development plan by 2025. Iran J Publ Health. 2009;38(1):13-6.

18. Bailey W, Phillips DR. Spatial patterns of use of health services in the Kingston metropolitan area, Jamaica. Soc Sci Med. 1990;30(1):1-12. [PubMed: 2305270].

19. Buor D. Distance as a predominant factor in the utilisation of health services in the Kumasi metropolis, Ghana. Geo J. 2002;56(2):145-57. doi: 10.1023/a:1022452311911.

20. Habib OS, Vaughan JP. The determinants of health services utilization in southern Iraq: a household interview survey. Int J Epidemiol. 1986;15(3):395-403. [PubMed: 3771078].

21. Cramer JS. Logit models from economics and other fields. Cambridge University Press; 2003.

22. Cramer J. An Introduction to the Logit Model for Economists, Timberlake Consultants. ; 2001.

23. Saeed B, Abdul-Aziz AR. Assessing the influential factors on the use of healthcare: Evidence from Ghana. Int J Business Soc Sci. 2013;4(1).

24. Elgazzar H. Income and the use of health care: an empirical study of Egypt and Lebanon. Health Econ Policy Law. 2009;4(Pt 4):445-78. doi: 10.1017/S1744133109004939. [PubMed: 19254431].

25. Woods CR, Arcury TA, Powers JM, Preisser JS, Gesler WM. Determinants of health care use by children in rural western North Carolina: results from the Mountain Accessibility Project. Pediatrics. 2003;112(2):e14352. [PubMed: 12897320].

26. Pourreza A, Khabiri R, Arab M, Akbari Sari A, Rahimi A, Toll A. Healthcare-seeking behavior in Tehran, Iran and factors affecting it. J School Public Health Inst Public Health Res. 2009;7(2):1-13.

27. Ishida Y, Ohde S, Takahashi O, Deshpande GA, Shimbo T, Hinohara S, et al. Factors affecting health care utilization for children in Japan. Pediatrics. 2011:2011-1321.

28. Chaze JP. Assessing household health expenditure with BoxCox censoring models. Health Econ. 2005;14(9):893-907. doi: 10.1002/hec.1042. [PubMed: 16127678].

29. Chau KL. Ecological analysis of health care utilisation for China's rural population: association with a rural county's socioeconomic characteristics. BMC Public Health. 2010;10:664. doi: 10.1186/1471-2458-10664. [PubMed: 21044343].

30. Blackwell DL, Martinez ME, Gentleman JF, Sanmartin C, Berthelot JM. Socioeconomic status and utilization of health care services in Canada and the United States: findings from a binational health survey. Med Care. 2009;47(11):1136-46. doi: 10.1097/MLR.ob013e3181adcbe9. [PubMed: 19786920]. 
31. Singh PK, Rai RK, Alagarajan M, Singh L. Determinants of maternity care services utilization among married adolescents in rural India. PLoS One. 2012;7(2):e31666. doi: 10.1371/journal.pone.0031666. [PubMed: 22355386].

32. Kavosi Z, Mohammadbeigi A, Ramezani-Doroh V, Hatam N, Jafari A, Firoozjahantighi A. horizontal inequity in access to outpatient services among Shiraz city residents, Iran. Journal of research in health sciences. 2015;15(1):37-41. [PubMed: 25821024].
33. Falkingham J, Akkazieva B, Baschieri A. Trends in out-of-pocket payments for health care in Kyrgyzstan, 2001-2007. Health Policy Plan. 2010;25(5):427-36. doi: 10.1093/heapol/czq011. [PubMed: 20332252].

34. Szwarcwald CL, Souza-Júnior PR, Damacena GN. Socioeconomic in equalities in the use of outpatient services in Brazil according to health care need: evidence from the World Health Survey. BMC health services research. 2010;10(1):217. 